\title{
INVENTORY DIGITAL MANAGEMENT USING STATISTICAL PROCESS CONTROL ANALYSIS IN HEALTHCARE INDUSTRY
}

\author{
Engy RASHED ${ }^{1} \mid$ Mostafa EISSA ${ }^{2, *}$ \\ 1 National Centre for Radiation Research and Technology, Cairo, Egypt, ORCID: 0000-0002-6593-378X \\ 2 Faculty of Pharmacy, Cairo University, Cairo, Egypt, ORCID: 0000-0003-3562-5935
}

Article Info:

Received : February 12, 2020

Revised : December 30,2020

Accepted : December 30, 2020

\section{Keywords:}

Box plot

Inventory control

Pareto diagram

SPC

Trending charts

DOI: $10.46238 /$ jobda.688641

\begin{abstract}
Inventory management in the healthcare industry is of prime importance to ensure the appropriate delivery of the medical and health products to the final customer in a reasonable time without shortage or overstocking of the goods. The achievement of this balance, in turn, is dependent on the production of the product in a timely manner through dynamic control of the inventory mobility of the input materials in the warehouse. In the present study, eight raw materials, which are used as excipients in healthcare products, were selected as a focus research group for analysis using statistical process control (SPC: process-behavior (trending/control) charts, Pareto plots, Box plot diagrams and Pie illustrations), namely Macrogolglycerides, MCC, Sodium Benzoic Sulfimide, Carmellose Sodium, Isofol 20, Citric Acid Hydrate, Ace K and Sodium Hydrate. Inventory autonomous management network was integrated with SPC software (Minitab $\left.{ }^{\circledR} \mathrm{v} 17.1 .0\right)$ using the generated database. A unique and simple index was created to prioritize and evaluate each material quantitatively based on material mass, rejection factor, deliveries intervals and the lag time before disposition. Isofol 20 and MCC contributed by about $70 \%$ as a material risk weight (MRW). This index is useful for objective comparative analysis, measurement of the degree of changes quantitatively and decision-making.
\end{abstract}

(c) 2020 JOBDA All rights reserved

\section{1 | INTRODUCTION}

Stock control and management of the incoming purchased items are crucial for the stability of the inventory in warehouses when considering appropriate stocking of the raw ingredients involved in the processing and manufacturing of the final products. Shortage and overstocking are undesirable routines in any organization that seeks to fulfill customers' needs within the appropriate time in a competitive market between different cooperate, institutions and firms (Bragg, 2018).

As the workload increases with a growing business, successful handling of the mobility of the material mass within an inventory becomes critical (Muller, 2011). Long-term trending and analysis of the dynamicity of the goods in warehouses might become an established activity as a part of a good storage practice (GSP), especially in a world were a digitalized computer autonomous control network facilitates data monitoring, segregation, integration and control (WHO Technical Report Series, 2008). The creation of customized databases based on the desired activity and process mining has become easy and valuable work that combines automatic inventory records and dataset generation with statistical processing and analysis platforms. The inventory management system would be useful in stock monitoring, decision-making and warehouse control.

One of the prime challenges in the inventory traffic business is the monitoring and control of goods dynamicity in the warehouse. Every delivered item in stock has its own weight and contribution to the workload in the organization of the affected industry. Establishment of quantitative metrics for the recognition and spot of the impact of each material

\footnotetext{
${ }^{*}$ Corresponding Author.

E-mail address: mostafaessameissa@yahoo.com (M. Eissa)
} 
delivered - based on its chronological trend - will be crucial in the assessment of goods weight over time objectively. In the present study, eight inactive raw materials commonly used as components in the preparation and formulation of healthcare products were selected and studied in the inventory over about ten years of data collection and monitoring using a unique approach by applying methodologies for quality improvements and process evaluation, taking into account both mass and time factors for the delivered shipments in the trending of the under-investigation materials. The current work aimed to develop a simple yet useful quantitative index through statistical analysis of long-term mobility of the goods in the warehouse.

\section{2 | MATERIALS AND METHODS}

Long-term inventory database was created for eight selected inactive raw materials that are widely used in compounding, mixing and preparation of formulations in a healthcare facility over about ten years. An inventory management platform was integrated with statistical process control (SPC) and analysis software through Excel dataset creation (Montgomery, 2013). Excel database was processed, segregated and stratified to obtain useful information before being analyzed using Minitab®v17.1.0. The focus group subjects were Macrogolglycerides (Caprylocaproyl), Microcrystalline Cellulose (MCC) with viscosity range $0.39-0.91$ dyne-second/square centimeter (dyn·s $/ \mathrm{cm}^{2}$ ), Sodium Benzoic Sulfimide (1,1-dioxo-1,2benzothiazol-3-one), Sodium Cellulose Gum (Carmellose Sodium), Isofol 20 (Kalcohl 200G), Citric Acid Hydrate (2-Hydroxypropane-1,2,3-Tricarboxylic Acid Hydrate), Ace K (Potassium 6-methyl-2,2-dioxo$2 \mathrm{H}-1,2 \lambda 6,3$-oxathiazin-4-olate) and Sodium Hydrate (Caustic Soda).

The inventory mobility of the stock mass understudy will be subjected to a multidimensional quantitative evaluation using Box-and-Whisker (Box plot or boxplot) plot to assess the average delivery quantity of the goods per shipment (Williamson, 1989; Elseviers, 2004). Moreover, rejection rates of the inspected materials could be determined using Pie diagram (Bodach, 2011). On the other hand, the dynamicity of the stock would be complemented using two types of the process-behavior or trending charts (Minitab 17, 2014; McLaughlin and Wakefield, 2015; Eissa, 2019a). First, a rare event $(G)$ control chart is used for charting the delivery arrival event intervals pattern to the warehouse. Second, hold or lag time in quarantine area - until full inspection and quality control analysis before disposition - might be examined using attribute charts to determine the degree of the consistency for the delay period until the materials become available for reallocation for use.
Consequently, adoption of an objective metric could be used as a comparative assessment index to measure the dynamic mobility of the materials in the stock. Similar risk metrics have been used before in other works for different applications (Eissa, 2019b). It was assigned as Material Risk Weight (MRW) and Upper Material Risk Weight (UMRW) for calculation at the mean and the upper control limit (UCL) from both types of the control charts, respectively. The simplest principle calculation was as follows:

$\mathrm{MRW}=\mathrm{M} \times \mathrm{F}(\mathrm{R}-\mathrm{T})$

$\mathrm{UMRW}=\mathrm{M} \times \mathrm{F}(\mathrm{TR}-\mathrm{TT})$

Where: $M$ is the average material quantity per shipment through ten years of monitoring (obtained from the boxplot of each material). $\mathrm{F}$ is the rejection factor that could be calculated as reciprocal of the conformance ratio. $\mathrm{R}$ and $\mathrm{TR}$ are the control limit (CL) and the threshold value of the upper control limit (UCL) of the delivery rate, respectively. T and TT are the control limit (CL) and the threshold value of the upper control limit (UCL) of the lag or hold time for the delivered material until the disposition, respectively. As the value of both index MRW and UMRW increase the dynamic risk for the material increases as it reflects the theoretical adjusted average material mass consumption per the effective time of use between deliveries of the good shipments. Otherwise, the cumulative effect in the headspace of the warehouse would occur for certain stored products. Both equations (1) and (2) were used in the comparative study of the indices of the raw material.

\section{3 | RESULTS AND DISCUSSION}

Inventory control in the healthcare industry is crucial to ensure continuous fulfillment of the consumers' demands in the market. A part of this activity includes an appropriate supply of medications in a timely manner through rigorous monitoring of the stock supplies for the medical components (Iqbal et al., 2017). This study focuses on a selected group of pharmaceutical excipients where unique yet simple methodologies could be used for analysis, prioritization of goods and decision making through decisive risk analysis-like tool. A useful means to achieve this goal was demonstrated by the application of SPC techniques using statistical software integrated with an inventory management platform (Lee and $\mathrm{Wu}, 2006$ ). The provided study would use the trend of the long-term database generated for the control, assess and monitor the dynamicity of the materials stock mobility.

The distribution pattern of the delivered quantities (in $\mathrm{Kg}$ ) of the raw materials over about ten years of recording is demonstrated in Figure 1 for the eight inactive pharmaceutical ingredients using Box-andWhisker (Boxplot or Box plot) diagram. The use of boxplot graph has been used previously in a different way for water inventory assessment (Broshears et al., 
2005). Medians and means values are shown along with exceptionally high mass shipments (indicated by asterisks). The biggest material average stock mass could be calculated was that of Isofol $20(1181.3 \mathrm{Kg})$ followed by Microcrystalline Cellulose (1119.44 Kg). While, the lowest material mean weights per shipments are Sodium Hydrate $(52.9 \mathrm{Kg})$ and Ace K(120.0 Kg), respectively. The opposite order could be observed for the medians in high masses and also reversed for the lowest two materials weights. Material mass (M) is one of the components that would be used in the ranking of the inventory goods. In between, the means and medians followed the same descending order as the following: Sodium Benzoic Sulfimide (404.8/300 Kg), Sodium Cellulose Gum (288.9/225 Kg), Citric Acid Hydrate (205.6/200 Kg) and Macrogolglycerides $(136.6 / 125 \mathrm{Kg})$, respectively.

The rate of arrival ( $R$ ) to the warehouse is another factor that affects material stock prioritization. This parameter could be illustrated in Figures 2 and 3 where rare event (or $G$ ) charts are used to measure the shipments delivery intervals and their daily rates (Glushkovsky, 1994). Red points marked by "4" pinpoints to alternating events in a row up and down around the mean line. This phenomenon was observed with Isofol 20. Interestingly, one point one chart of Sodium Cellulose Gum showed red alarm signed by "B" referring to Benneyan test for consecutive points indicating incidents of arrivals that occurred in the same day or successive order which may require a further investigation. Different types of alarming signals in the constructed control charts have been detailed before in a different work (Eissa et al., 2015)). The frequency of the arrival to the warehouse is in the following ascending order (indicator by UCL/CL expressed as days): Oleoyl Macrogolglycerides (1679/175), Ace K (1179/123), Sodium Cellulose Gum (981/102), Sodium Hydrate (737/76), Citric Acid Hydrate (720/75), Microcrystalline Cellulose (708/73), Isofol $20(559 / 58)$ and finally Sodium Benzoic Sulfimide (489/50).

The third aspect that impacts wares weight is the delay time (T) till release from the inventory hold area for the production and further processing. This lag time could be viewed statistically through attribute control charts Figures 4 and 5 for each excipient using Laney's approach (Laney, 2002). Red dots marked by "1" are aberrant values reflecting delays in the material disposition over the normal trend by more than 3 standard deviations from the center line. One the other hand, alraming points denoted by "2" indicate shifts in the inspection mean time when nine succesive points are on the same side from the average line. The lag time (measured as UCL/CL of days taken in the quarantine area in the warehouse) was found in the following descending order: Sodium Cellulose Gum (118, 32) then Microcrystalline Cellulose $(72,24)$ followed by
Ace K $(66,26)$, Citric Acid Hydrate $(69,22)$, Isofol 20 $(63,22)$, Oleoyl Macrogolglycerides (56/23), Sodium Benzoic Sulfimide $(50 / 15)$ and at last Sodium Hydrate $(48,13)$.

The fourth term that might contribute to the raw materials weight risk is the non-conformity $(F)$ ratio or rejection rate. Figure 6 shows Pie (circle) charts for the rejection percent/Rejection factor (Crow, 2006) from the total received shipments during this research analysis in the ascending order as the following: Macrogolglycerides (0.0/1), Microcrystalline Cellulose (0.4/1.004), Sodium Benzoic Sulfimide (1.9/1.019), Sodium Cellulose Gum (2.2/1.022), Isofol 20 (2.3/1.024), Citric Acid Hydrate (4.2/1.044), Ace K (5.9/1.063) and Sodium Hydrate (14.7/1.172).

From the above segmental analysis, a material risk weight could be calculated for each medicinal component under the focus study estimated for the means and the upper thresholds. The adopted index would assess the raw materials inventory mobility in a simple way that could help in prioritization and decision making in the stock management control. On the same line, other works previously have shown different approaches in the application of the quantitative risk evaluation in healthcare field (Van Sciver, 1990; Ahmed Eissa, 2019). Table 1 illustrates the derived inidividual parameter for each good and the final calculated index values as Material Risk Weight (MRW) and Upper Material Risk Weight (UMRW). Pareto diagrams illustrate these values for prioritization of the material importance ranking in Figure 7 . The greatest inventory mobility weights with about 70\% index contribution stemmed from Isofol 20 and Microcrystalline Cellulose. Thus, this ranking shows that both of these materials are the most critical stock items with the greatest dynamicity as could be weighted from either indexes i.e MRW and UMRW. 
Figure 1. Box Plot Diagrams Of Excipients Showing The Distribution Pattern Of Shipment Delivered Quantities (in Kg) With Median And Mean Values Demonstrated (Asterisks Are Indications Of Aberrant Values)

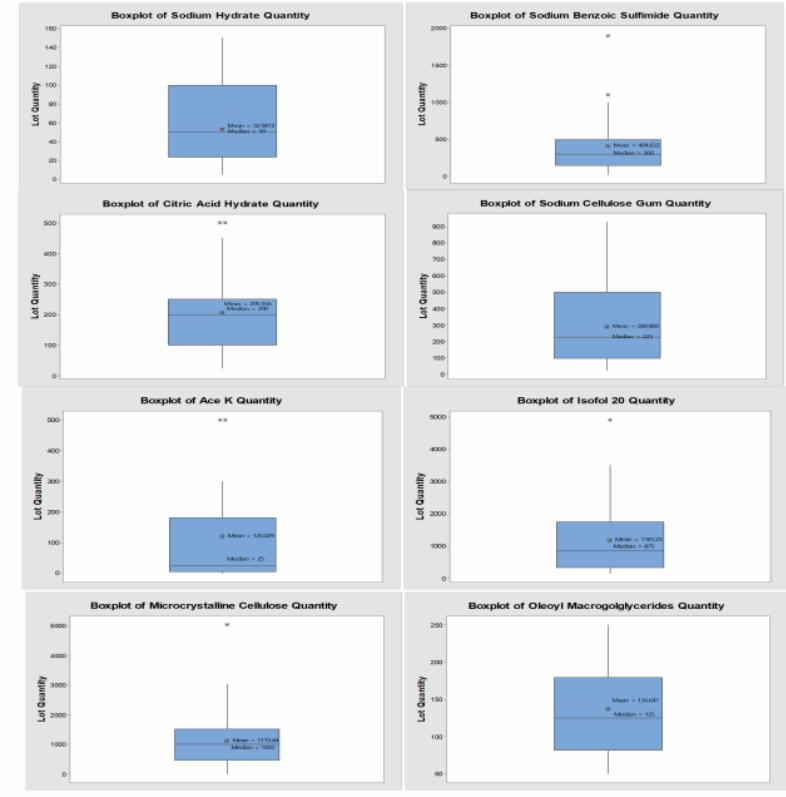

Figure 2. Rare Event Control Charts In The Monitoring Sodium Hydrate, Sodium Benzoic Sulfimide, Citric Acid Hydrate And Sodium Cellulose Gum

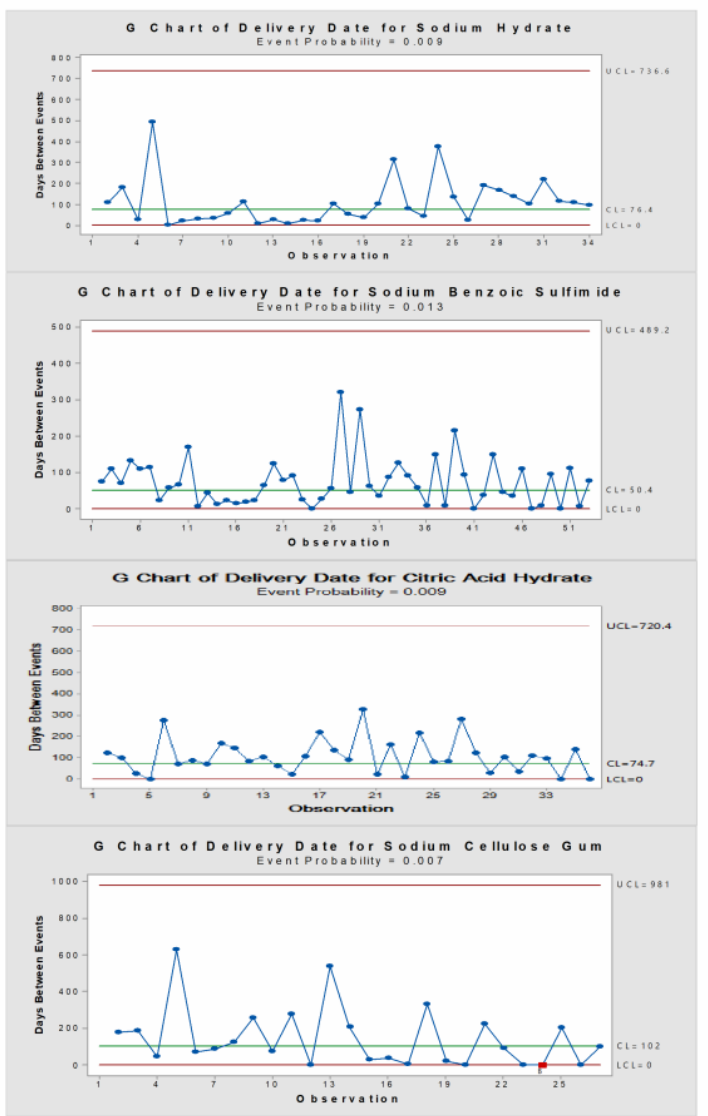

Figure 3. Rare Event Control Charts In The Monitoring Isofol 20, Ace $\mathrm{K}$, Oleoyl Macroglycerides And Microcrystalline Cellulose

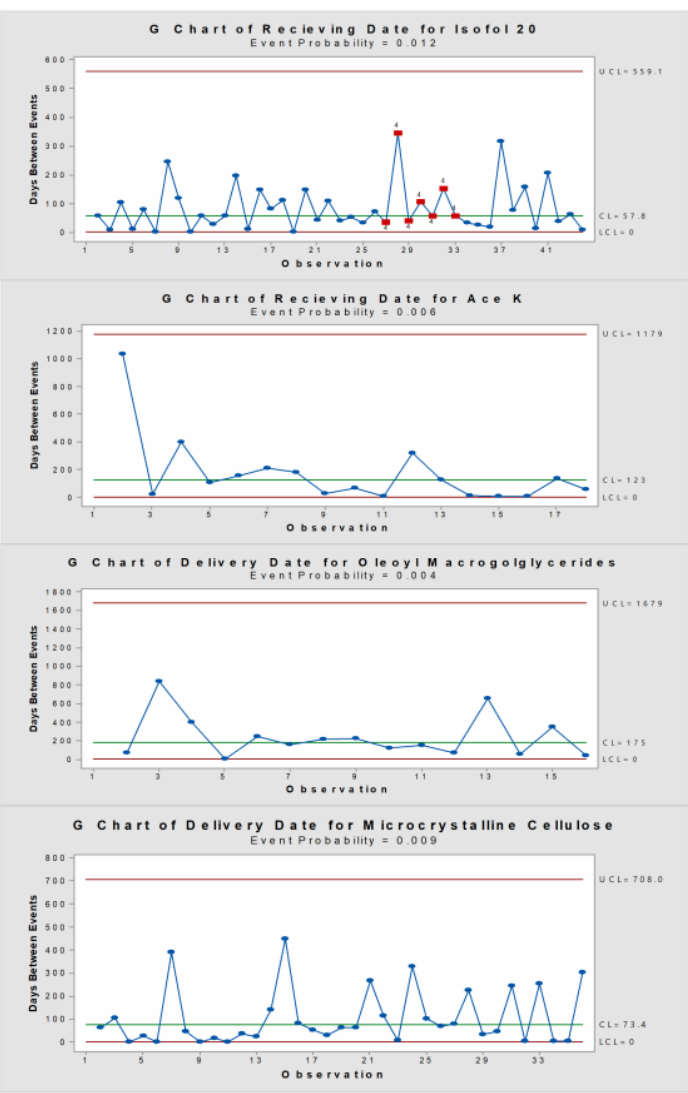

Figure 4. Delay Time Monitoring Control Charts In The Monitoring Sodium Hydrate, Sodium Benzoic Sulfimide, Citric Acid Hydrate And Sodium Cellulose Gum

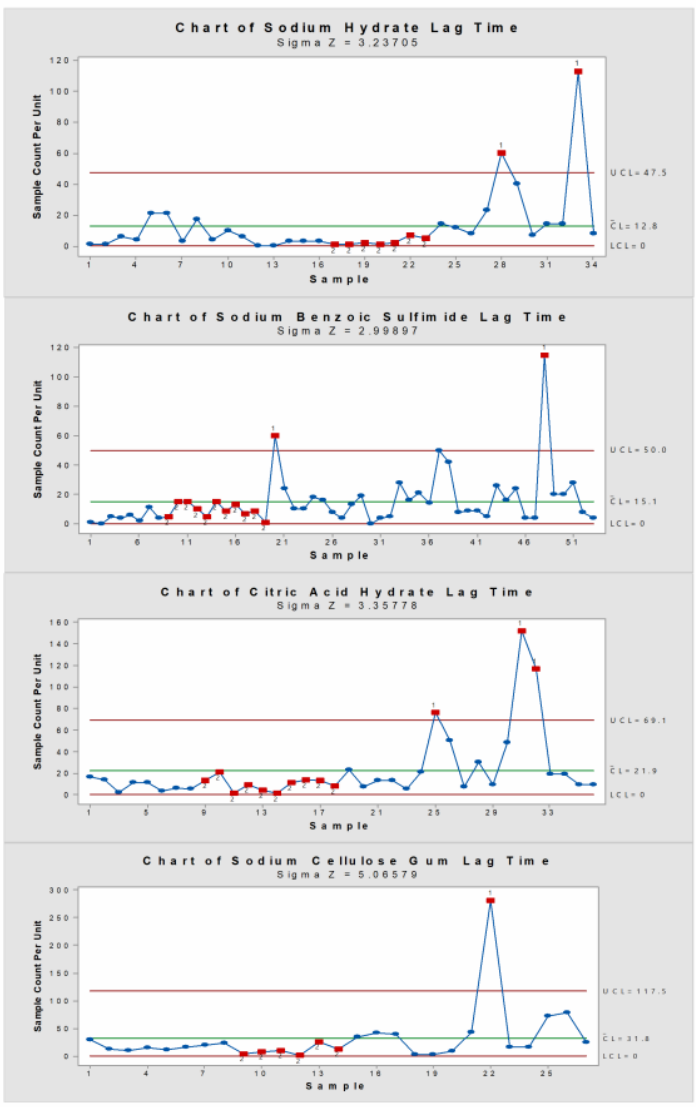


Figure 5. Delay Time Monitoring Control Charts In The Monitoring Isofol 20, Ace K, Oleoyl Macroglycerides And Microcrystalline Cellulose

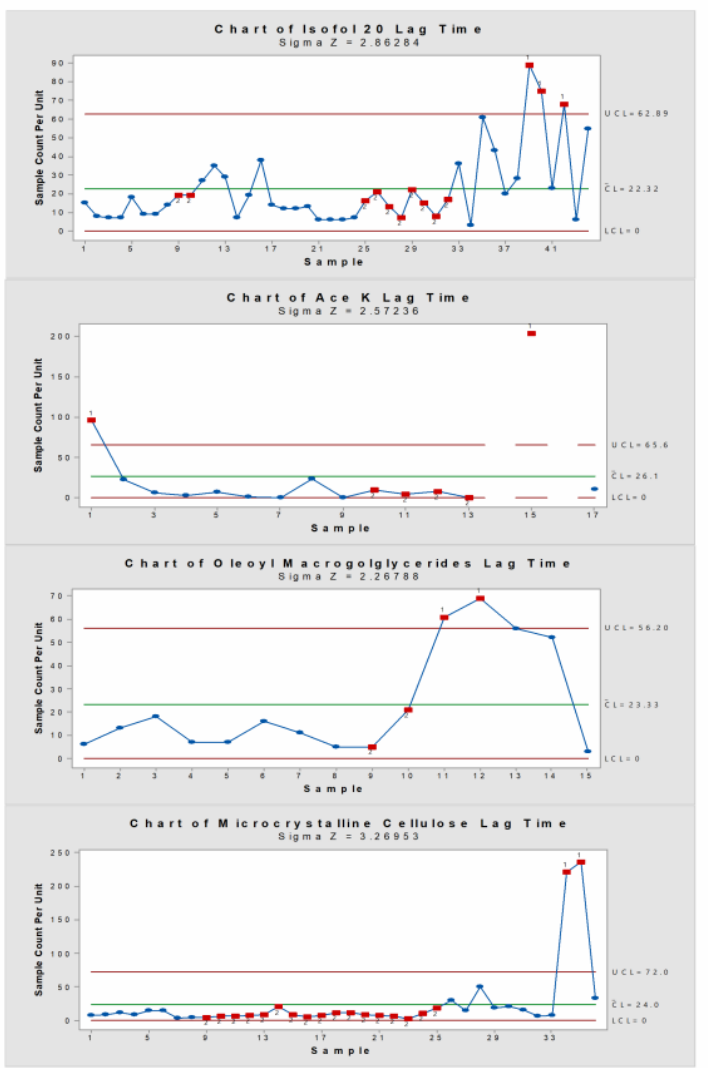

Figure 6. Proportion Of Conforming, Non-Complying And Pending (If Any During Data Collection) Of The Arrived Under-Study Materials At Warehouse

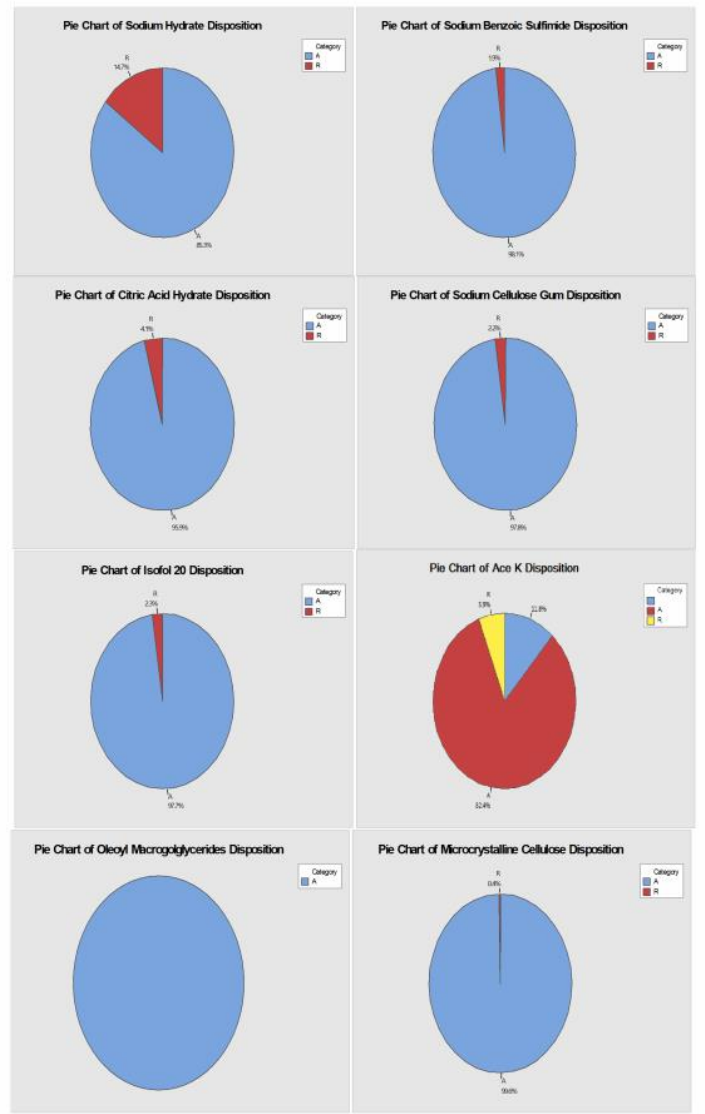

Table 1. Estimated Material Risk Weight (MRW) and Upper Material

\begin{tabular}{|l|c|c|c|c|c|c|c|c|}
\hline \multicolumn{10}{c|}{ Risk Weight (UMRW) } \\
\hline Raw Material & TR & $\mathrm{R}$ & $\mathrm{M}$ & $\mathrm{TT}$ & $\mathrm{T}$ & $\mathrm{F}$ & $\mathrm{UMRW}$ & $\mathrm{MRW}$ \\
\hline $\begin{array}{l}\text { Oleoyl } \\
\text { Macroglycerides }\end{array}$ & 1679 & 175 & 136.6 & 56 & 23 & 1.000 & 0.084 & 0.899 \\
\hline Sodium Hydrate & 737 & 76 & 52.9 & 48 & 13 & 1.172 & 0.090 & 0.984 \\
\hline Ace K & 1129 & 123 & 120.0 & 66 & 26 & 1.063 & 0.120 & 1.315 \\
\hline Citric Acid Hydrate & 720 & 75 & 205.6 & 69 & 26 & 1.044 & 0.330 & 4.381 \\
\hline $\begin{array}{l}\text { Sodium Cellulose } \\
\text { Gum }\end{array}$ & 981 & 102 & 288.9 & 118 & 32 & 1.022 & 0.342 & 4.218 \\
\hline $\begin{array}{l}\text { Sodium Benzoic } \\
\text { Sulfimide }\end{array}$ & 489 & 50 & 404.8 & 50 & 15 & 1.019 & 0.940 & 11.785 \\
\hline $\begin{array}{l}\text { Microcrystalline } \\
\text { Cellulose }\end{array}$ & 708 & 73 & 1119.4 & 72 & 24 & 1.004 & 1.767 & 22.936 \\
\hline Isofol 20 & 559 & 58 & 1181.3 & 63 & 22 & 1.024 & 2.439 & 33.601 \\
\hline
\end{tabular}

Figure 7. Pareto charts for prioritization of Material Risk Weight (MRW) and Upper Material Risk Weight (UMRW)

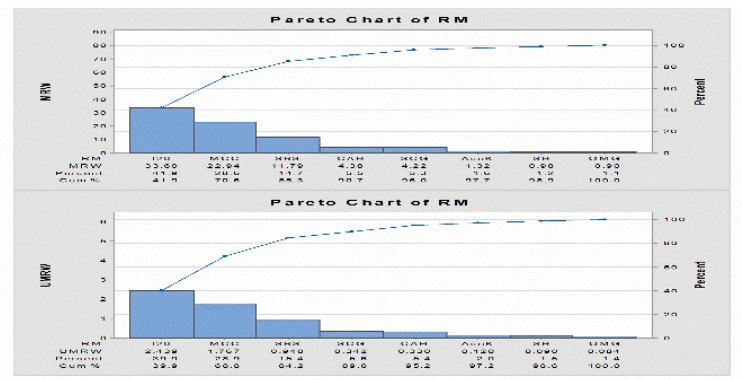

I20: Isofol 20, MCC: Microcrystalline Cellulose, SBS: Sodium Benzoic Sulfimide, CAH; Citric Acid Hydrate,

SCG: Sodium Cellulose Gum, SH: Sodium Hydrate, OMG: Oleoyl Macroglycerides

\section{4 | CONCLUSION AND SUGGESTIONS}

Inventory dynamic management is important for the control of the goods mobility in the organization stock. Items' weight and criticality are time-dependent and affected by changing market demands. Thus, quantitative metrics would be useful for an objective assessment of the value of the raw materials during a specific time frame. The presented index is useful in prioritization and weighing the material stock value as a supportive tool for decision-making in everyday business control and disposition where a successful organization goal depends largely on the handling of ever-escalating challenges such as the increase of work demand with limited resources as could be evident by the increase of delay times until the final disposition spotted by the attribute charts. This warning signal in the study could be useful for the administration for resources management and prioritization to solve delay issues for the affected items. Further work may be required in the future to trace the raw materials dynamicity at shorter intervals such as yearly recording to follow the fluctuations in the demands of the stock for each delivered input constituent in the final product. 


\section{REFERENCES}

Ahmed Eissa, M. E. (2019). The use failure mode and effects Analysis as Quantitative Risk Analysis Tool. Opinion| J App Sci| Redelve: RD-APS 10009.

Bodach, V. (2011). Gráficas circulares. Mankato, Minn.: Capstone Press.

Bragg, S. (2018). Inventory management. Centennial, Colorado: AccountingTools, Inc.

Broshears, R. E., Akbari, M. A., Chornack, M. P., Mueller, D. K. and Ruddy, B. C. (2005). Inventory of ground-water resources in the Kabul Basin, Afghanistan. U. S. Geological Survey.

Crow, L. H. (2006). Useful metrics for managing failure mode corrective action. In RAMS'06. Annual Reliability and Maintainability Symposium, 2006. (pp. 247-252). IEEE.

Eissa, M. (2019a). Rare event control charts in drug recall monitoring and trend analysis of data record: A multidimensional study. Global Journal On Quality And Safety In Healthcare, 2(2), 34-9. doi: 10.4103/jqsh.jqsh_3_19

Eissa, M. (2019b). A Long-Term Impact Study of Bacterial Outbreak Using Control Chart-Risk Assessment Combination. Worldwide Medicine, 1(4), 117-122. doi: 10.5455/ww.48101

Eissa, M. E., Seif, M., and Fares, M. (2015). Assessment of purified water quality in pharmaceutical facility using six sigma tools. International Journal of Pharmaceutical Quality Assurance, 6(02), 54-72

Elseviers, M. (2004). STATISTICS CORNER: THE BOX PLOT: An alternative way to present a distribution of observations. EDTNA-ERCA Journal, 30(2), 114-116. doi: 10.1111/j.17556686.2004.tb00345.x

Glushkovsky, E. A. (1994). 'On-line'g-control chart for attribute data. Quality and Reliability Engineering International, 10(3), 217-227.
Iqbal, M., Geer, M., \& Dar, P. (2017). Medicines Management in Hospitals: A Supply Chain Perspective. Systematic Reviews In Pharmacy, 8(1), 80-85. doi: 10.5530/srp.2017.1.14

Laney, D. B. (2002). Improved control charts for attributes. Quality Engineering, 14(4), 531-537.

Lee, H., \& Wu, J. (2006). A study on inventory replenishment policies in a two-echelon supply chain system. Computers \& Industrial Engineering, 51(2), 257-263. doi: 10.1016/j.cie.2006.01.005

McLaughlin, K. M., and Wakefield, D. B. (2015). An Introduction to Data Analysis Using Minitab® 17. University of Connecticut: Pearson Education, Incorporated.

Minitab 17. (2014). Getting Started With Minitab 17. USA: Minitab, Inc.

Montgomery, D. (2013). Statistical quality control. Hoboken, N.J.: Wiley.

Muller, M. (2011). Essentials of inventory management. New York: AMACOM.

Van Sciver, G. R. (1990). Quantitative risk analysis in the chemical process industry. Reliability Engineering \& System Safety, 29(1), 55-68.

WHO Technical Report Series. (2008). WHO Expert Committee on specifications for pharmaceutical preparations. Revista Do Instituto De Medicina Tropical De São Paulo, 50(3), 144-144. doi: 10.1590/s0036-46652008000300013

Williamson, D. (1989). The Box Plot: A Simple Visual Method to Interpret Data. Annals of Internal Medicine, 110(11), 916. doi: 10.7326/0003-4819110-11-91. 